\title{
Financial stability role on climate risks, and climate change mitigation: Implications for green economic recovery
}

\author{
Licheng Sun ${ }^{1} \cdot$ Sui Fang ${ }^{1} \cdot$ Sajid Iqbal ${ }^{2}$ - Ahmad Raza Bilal ${ }^{3}$
}

Received: 5 October 2021 / Accepted: 5 November 2021 / Published online: 13 January 2022

(c) The Author(s), under exclusive licence to Springer-Verlag GmbH Germany, part of Springer Nature 2022

\begin{abstract}
As a response to the topic of how financial stability might be used to effectively finance for the mitigation of climate change and climate risks, it is important to look at the carbon risk that is still present in G-5 nations. The goal of our research is to determine the impact of financial stability on climate risk in order to effectively manage climate mitigation efforts. A technique called GMM is used to achieve this goal. Climate change mitigation was found to be substantial at 18 percent, while financial stability and carbon hazards were found significant at 21 percent, according to the conclusions of the study. Furthermore, the G-5 countries' $19.5 \%$ correlation between financial stability and emissions drift, which raises climate change concerns, is noteworthy. In order to implement green economic recovery methods, one of the most strongly regarded approaches to mitigating climate change and ensuring long-term financial potential at the national scale, a country's financial stability is required. The research on green economic expansion also offers the associated stakeholders with detailed policy implications on this relevance.
\end{abstract}

Keywords Financial stability · Climate risks · Climate change mitigation · Carbon drifts · Green economic recovery

\section{Introduction}

Despite the fact that climate change is widely accepted as a significant means of economic system risk (Alemzero et al. 2021) and the scholars and policymaker's community has begun to pay growing interest to climate finance ( $\mathrm{Li}$ et al. 2021a, b), there is still a massive disparity in the progress of techniques that permit us to effectively evaluate weather financial problems (Iqbal et al. 2021a, b). Until now, this is

Responsible Editor: Nicholas Apergis

Sajid Iqbal

sajidiqbal.edu@gmail.com

Licheng Sun

sunsee213@ujs.edu.cn

Sui Fang

1000003731@ujs.edu.cn

Ahmad Raza Bilal

abilal@su.edu.om

1 School of Management, Jiangsu University, Zhenjiang 212013, China

2 KUBEAC, University of Management \& Technology, Sialkot Campus, Pakistan

3 Faculty of Business, Sohar University, Sohar, Oman the first time a journal has dedicated a whole issue to the topic of climate-related risks and financial stability (Li et al. $2021 \mathrm{a}, \mathrm{b})$. For the transition to a low-carbon society, this relationship has major ramifications, and it poses fundamental methodology questions in academia (Anh Tu et al. 2021).

It is important to note that the unique features of climate risks (such as high uncertainty, quasi, and unobserved heterogeneity) provide significant hurdles to established macroeconomic and financial analytical approaches (Iqbal et al. 2021a, b). Before making significant difference, researchers must address the basic concerns highlighted by climate threats, going far beyond renaming current models as climate clean or green (Ahmad et al. 2021). Second, new financial risks arise as a result of global warming. The answer is simple; it is based on what we have learned about climate change over the previous decades (Puaschunder 2016). Extreme weather events and other forms of risks will have increased risk of negative socioeconomic repercussions as a due to climate change unless adequate change mitigation measures are taken across a wide range of economic sectors and geographical areas (Carney 2015). For energy policies to be effective in achieving the low-carbon transition and averting catastrophic climate change, both industrialized and developing economies will need to undergo significant transformations (Bovari et al. 2020). This could cause 
considerable disturbance, negatively affecting a few business activities and industries while creating opportunities for others (Weber et al. 2018).

Due to these climates change-related economic repercussions, companies and governments may have to make changes to the value of financial assets they hold or issue (Neuhoff et al. 2009). The obligations of insurance companies and the default rate on loans given by financial institutions might be harmed as a result (Chen et al. 2020). Because of the financial interconnectivity, climate-related financial transfer pathways may be magnified and have significant spillover impacts on the actual economy (Iqbal and Bilal 2021). Since the natural impacts of climate change and the low-carbon transition have broad economic ramifications, climate risks are important for the financial viability of specific organization (Kim et al. 2020). Climate risk affects economic security on a national and international scale because of the correlation of repercussions and the interconnectivity of organizations and industries (Sholdarov and Mullaboev 2019).

Changing climate is already part of the risk assessment of financial institutions and will be included in future stress tests (Anadu et al. 2020). The European Commission (EC) established the High-Level Expert Group on Sustainable Finance (HLEG) in 2016 (Alqahtani and Mayes 2018; Kopp et al. 2017; Buckmann et al. 2021).

Temperature changes may harm assets and manufacturing capacity, raising the credit risk for institutions and creating financial losses for the insurance industry (Yin 2019). This might lead to a decline in government funding. Unexpected and unexpected changes in asset values (Trinh et al. 2020) and changes in defaults for whole assets classes may occur as a consequence of the decarburization society. This might create economic surprises for money managers as well as investment firms and bankers' holdings. A chaotic development of low industry, in which capitalists fail to properly foresee the effect of climate regulations on their business models, poses the greatest danger to financial stability in the context of climate transition risk (Anarfo and Abor 2020). Companies that rely on fossil fuel production or use for their operations and income may suffer financially, giving birth to the so-called stranded assets. In turn, this might have a detrimental impact on the value of business contracts and holdings that are linked to those businesses, such as bank loans and pension fund stock and bond holdings (Phan et al. 2021). Furthermore, as was the case during the global financial crisis, the greater level of interconnection among financial players may magnify damages for both individuals and the financial sector (Drobyazko et al. 2020).

The major goal of this research is to thoroughly examine the effectiveness of spontaneous changes in household choices in reducing climate change. The energy and carbon rebound impacts are seen throughout the whole economy. We also look at whether voluntary initiatives might be supplemented by a carbon fee to counteract the negative potential impacts. For the Catalan economy, a recursive-dynamic economy-energy-environment CGE model is utilized, and a set of 75 possible actions is evaluated with a total of 1560 runs. The carbon price required to offset the caused rebound impacts is also estimated for the particular intensity. Aside from this one, there is not a research that goes into such detail and depth, or employs this technique.

\section{Literature review}

As a low-cost but successful approach of reducing carbon emissions and so mitigating climate change, voluntary measures taken by families or changes in consumption patterns are frequently encouraged by authorities and other organizations (Flori et al. 2021). Use of more energy-efficient lighting, purchase of energy-saving household equipment, container change, and dietary changes are examples of these (Liu et al. 2020). If you are doing it unknowingly, you are just wasting money on things you might be spending less money on (Lasco et al. 2014). It is possible that reallocating funds will have potential impacts, lowering or countering any drop in emission projected based on their energy (or carbon) efficiency (Tong and Ebi 2019). Re-spending simulation is a term used in the rebound effect literature to describe the process of examining the many ways these newly resources available may be spent (Creuitzig et al. 2015). The Khazzoom-Brookes hypothesis or the Jevons' dilemma describes the outcome when these acts lead to an increase in energy usage (Arbuckle et al. 2015). This issue is not limited to energy resources.

While saving energy may seem to be a cheap solution to achieve environment and power objectives, Demski et al. (2017) points out that it ignores the rebound effect. A number of studies have used various modelling frameworks and assumptions to experimentally analyzes this problem (Warren et al. 2013). According to earlier research, implementing "green" consumption patterns did not cut carbon emissions as projected and, in some instances, instead raised them when applying mixed input-output techniques on a sample of Swedish families in Sweden (Weber 2010). A combined rebound impact of $34 \%$ is predicted for UK households employing composite input-output approaches for three reduction interventions (Viscusi and Zeckhauser 2006). Targeting re-spending on goods and services with a low greenhouse gas (GHG) intensity found a rebound of around $12 \%$, while re-spending on goods and services with a high GHG intensity was found to backfire (Moser and Luers 
2008). Power conserving measures taken by Australian homes are anticipated to have a 5\% rebound impact. Using home requester and LCA techniques, Doelman et al. (2020) reported rebound effects of 4-24\% for electricity and motor fuel saving. Using environmentally extended input-output approaches, and is revealed that for Norwegian families, rebound effects ranged from 40 to $59 \%$.

The studies suggested to include standard economic impacts when simulating changes in industry pricing and volumes caused by macroeconomic uncertainty (Mills 2007). They are capable of incorporating more sophisticated socioeconomic agency behavior formulas than methods that use fixed coefficients, such as input-output analyses (Mi et al. 2019). In order to estimate the rebounding from sufficient policies, preservation, or volunteer initiatives, tracking the general equilibrium and inter-industry impacts is crucial. CGE model simulations are often used in research on carbon pricing, and these studies commonly analyze the extent of leakage, that is, how the increase in carbon in nations without a carbon price offsets the decrease in pollution in those nations (Stephens et al. 2009). In the similar vein, we are simulating rebound effects here (Hasegawa et al. 2018).

Prior research in three areas will be reviewed and contrasted with the findings of this study in order to show the value of this research (Campbell et al. 2016). The very first body of research focuses on supply chain carbon price regulations. Reduced expenditure and different supply chain energy configurations have been studied in the literature to determine the best strategy for reducing carbon emissions (McMichael and Lindgren 2011). Research in the past has concentrated on how carbon taxes affect manufacturing distribution network plans and has substantial management consequences for supply chain participants and the state. Prior studies reveal (Sussman and Freed 2008). Carbon tax legislation takes into account the impact of risk aversion on a two-tier supply chain, and when a firm should make lowcarbon technological investments. This research looked at how carbon emission costs affect 2 nd biofuels distribution networks in order to accomplish sustainable and low overall cost objectives (Barnett 2003).

Carbon tax and limit were also included in Wennersten et al. (2015) supply chain, and a responsible structure was built to limit overall carbon emissions. Multiple-delivery strategy was explored by Rickards et al. (2014) instead of prior fixed carbon costs. A worldwide sustainable supply chain model with various levels of credit terms and a solitary policy was developed to achieve mutual coordination in financial assistance while also lowering carbon emissions. Using a carbon foot print method, Swim et al. (2011) looked at how a carbon tax would distribute total carbon emissions across supply chain participants.

In a symmetrical commercial supply chain, Revi (2008) looked at the effect of emission reduction investments. It is more likely that a supply chain with an asymmetric power structure will have a significant influence on operational choices, particularly in light of the existing financial inequity between the competing producers (Howell et al. 2016). Publications cited above also assumed that supply chain participants had enough cash to carry out operational choices and low-carbon investment. Although small and medium-sized enterprises (SMEs) are prone to the problem of financial limits when implementing their choice is important. This results in reduced supply chain economic and environmental performance (Bain et al. 2012). Consequently, research into ways to relieve and enhance the environmental and economic performance of involved parties with financial imbalance is required. The second stream of literature related to this study is climate financing (Barbi and Costa Ferreira 2017). Current supply chain finance research has focused on capital-constrained supply networks that are one to one (Ogunbode et al. 2019).

According to Ivanova et al. (2020), TCF may accomplish two-echelon supply chain coordination while taking supplier perverse incentives and expensive finance costs into account. Devalkar and Krishnan According to Lee (2012), trade credit may help suppliers coordinate their supply chains. According to the findings, markdown allowance and TCF may encourage suppliers to coordinate their actions with merchants in order to maximize their combined profit margins. The TCF may also be compared against other types of financing, such as directed funding (such as commercial bank funding, or BCF), to see which is the best option for a shop with little capital. According to Iqbal et al. (2021), trade credit may help supply chain efficiency.

Additionally, other researchers studied the financial aspects of the supply chain that are affected by emissions. Iqbal and Bilal (2001), for example, looked at the value of pledging carbon emission permits under the cap-and-trade system for an emission-dependent firm. Manufacturers who are emission reliant but have limited cash have partial credit guarantees and trade credits to help them carry out operational choices and investments to reduce emissions. The literature on one-to-one supply networks has recently been broadened by some researchers to include competitive supply chains with capital limitations as well.

\section{Methodology}

\section{Data and measures}

Dataset from G-5 nations has been used by our panel from 2009 to 2018 data. According to Park and Gupta (2012) and Windmeijer (2005). The research combines two types of risk commonly seen in the research to represent financial stability with climate risks and climate change mitigation. For 
financial stability, debt allowances indicate the bank's covering for potential credit losses when analyzing credit risk. The allowances factor measures the bank's projected loss on loans as a percentage of gross loans (Ronchetti and Trojani, (2001). Decreases in provision thus reflect a drop in the degree of climate risk coverage.

In terms of climate risks mitigation, banks have a sufficient capital (buffer) equal to the amount of capital they hold over the bare minimum required by regulators. The buffer is a determinant of economic firms' capital relative to regulatory minimums, which is expressed as a difference between the two. More buffer means reduced bank collapse risk (Inoune et al, 2006). It is also possible that as a result of the economic cycle, banks maintain a procyclical buffer, reducing it during times of expansion and raising it during recessions (Alan et al. 2009), thereby magnifying the loop and hence escalating financial stress risks (Gupta and Kashiramka, 2020; Nair and Anand, 2020). Similarly, climate risks and climate change mitigation are taken as other variables of study which are operationalized in the study model.

\section{Empirical estimation through GMM}

To predict the results, the researchers employed the generalized method of moment approach. Estimation and inference in models based on moment conditions benefit greatly from the generalized method of moments (Hansen, 996). These improvements involve, among other things, how well it performs with small and intermediate datasets and how well it holds up against minor deviations from the anticipated model. Our research in this field focuses on the generalized technique of trimmed moments, which is more resilient to large model errors than other current approaches and can yield estimates with almost the same variance as the original GMM under many circumstances. When we say that an estimate is resilient to little or big departures from the model, we imply that it can modify arbitrary estimations if the population is adjusted in some manner. Most commonly used GMM estimators have a break down measure that asymptotically equals zero.

Due to sampling mistake, a system of sample moment conditions will not always get a resolution if the number of criterion is greater than the number of unknown parameters. An additional optimization, such as weighted distance minimization or quasi-likelihood maximization, is generally used to estimate the variable. An estimator's qualities might vary depending on how an auxiliary issue is put up. First-order asymptotic efficiency among the class of GMM estimators based on the same moment conditions was suggested by Hansen et al. (1996) as a two-distance reduction with updating weighting. Alternative approaches are quite well for improving the estimator's tiny characteristics.

To be more specific, the finding applies to the classical minimal distance estimate, which is regarded in this research as a workable two-step linearized GMM. So, for every ith remark of an arbitrary $\mathrm{N}$ sample, it is supposed as

$E\left[m_{i}\left(\gamma\left(\theta_{o}\right)\right)\right]=0$

Meanwhile, a limited parameter section which is denominated as $\gamma$ is truly highlighted in Eq. (1) and is supposed that the an parallel solution does exists, denominated with $\hat{\gamma}$ in Eq. (2):

$\frac{1}{N} \sum_{i=1}^{N} m_{i}(\hat{\gamma})=0$

By keeping in view the answers to the reduction issues, which is mathematically represented in the Eq. (3) is shown as ${ }^{\wedge} \gamma$. This is due to the substituting effect of a weighted matrix with a random solution, and shall not influence the solution of the GMM technique to apply for empirical inference.

$\min _{\gamma} \sum_{i=1}^{N} m_{i}(\gamma)^{\prime}\left(\sum_{i=1}^{N} m_{i}(\hat{\gamma}) m_{i}(\hat{\gamma})^{\prime}\right)^{-1} \sum_{i=1}^{N} m_{i}(\gamma)$

More specifically, a limited nature of measurement parameters, such as, $\gamma$ that is treated as the systematic parameter function - and this is dominated with $\theta$ in Eq. (4). Thus, Eq. (4) also presents a solution to measure this, and it elevates the reduced form weighting estimator (RWE):

$\min _{\theta} \sum_{i=1}^{N} m_{i}(\gamma(\theta))^{\prime}\left(\sum_{i=1}^{N} m_{i}(\widehat{\gamma}) m_{i}(\hat{\gamma})^{\prime}\right)^{-1} \sum_{i=1}^{N} m_{i}(\gamma(\theta))$

The noteworthy aspect of the RWE is that the loading array is assessed at threshold regression identifying rather than architectural ones. The grading is (first-order) optimum due to the obvious relationship which is empirical represented in Eq. (5). The scaling matrices in (5) are transformed with here in typical two-step GMM by

$\left(\sum_{i=1}^{N} m_{i}(\gamma(\tilde{\theta})) m_{i}(\gamma(\tilde{\theta}))^{\prime}\right)^{-1}$

To compute the reduced form of weighting estimators (RWE), Eq. (5) is further elaborated in Eqs. (6), (7), and (8) respectively. This is to estimate the two-step GMM technique:

$B_{I}+B_{G}+B_{\Omega}$

Using the findings about GMM which directed that—one may deduce the RWE higher-order asymptotic bias directly from RWE; 
$B_{G}=-\left(G^{\prime} \Omega^{-1} G\right)^{-1} E\left[G_{i}^{\prime} P g_{i}\right] / N$

In which

$G_{i}=\frac{\partial m_{i}\left(\gamma_{0}\right)}{\partial \gamma} \frac{\partial \gamma\left(\theta_{0}\right)}{\partial \theta}, G=E\left[G_{i}\right], \Omega=E\left[m_{i}\left(\gamma_{0}\right) m_{i}\left(\gamma_{o}\right)^{\prime}\right]$

Associated with the CUE bias, the extended notation is

$\widehat{\mathrm{m}}_{1}^{L C M}\left(\theta_{1}\right)=\sum_{i=1}^{N} m_{i 1}^{L C M}\left(\widehat{\gamma}, \theta_{1}\right)=\sum_{i=1}^{N} \mathbf{z}_{i}^{\prime}\left(y_{i 1}-\mathbf{z}_{1} \delta_{1}-\mathbf{y}_{2} \alpha\right)$

$m_{i 1}^{L C}(\gamma, \alpha)=m_{i 1}\left(\gamma_{1}\right)-\mathbf{z}_{i}^{\prime}\left(\mathbf{y}_{i 2}-\mathbf{z}_{i 1} \boldsymbol{\delta}_{21}-\mathbf{z}_{i 2} \boldsymbol{\delta}_{22}\right) \alpha$

Equations (9) and (10) are further extended to compute simulations and estimate the two-step GMM estimated of the study:

$$
\min _{\theta_{1}}\left(\sum m_{i 1}^{L C M}\left(\theta_{1}\right)\right)^{\prime}\left(\sum m_{i 1}^{L C}\left(\theta_{1}\right) m_{i 1}^{L C}\left(\theta_{1}\right)^{\prime}\right)^{-1}\left(\sum m_{i 1}^{L C M}\left(\theta_{1}\right)\right)
$$

where if the contingent average criteria is valid, then BG is equal to 0 .

$$
\begin{aligned}
m_{i 1}^{L C M}\left(\theta_{1}\right) & =m_{i 1}(\hat{\gamma})+\frac{\partial m_{i 1}(\hat{\gamma})}{\partial \gamma_{1}}\left(\gamma_{1}\left(\theta_{1}, \hat{\gamma}_{2}\right)-\widehat{\gamma}_{1}\right) a n d m_{i 1}^{L C}\left(\theta_{1}\right)=m_{i 1}(\hat{\gamma}) \\
& -\left[\sum \frac{\partial m_{i 1}(\hat{\gamma})}{\partial \gamma_{2}^{\prime}}+\sum \frac{\partial m_{i 1}(\hat{\gamma})}{\partial \gamma_{1}^{\prime}} \frac{\partial \gamma_{1}\left(\theta_{1}, \hat{\gamma}_{2}\right)}{\partial \theta_{2}^{\prime}}\right]\left(\sum \frac{\partial m_{i 2}\left(\hat{\gamma}_{2}\right)}{\partial \gamma_{2}^{\prime}}\right)^{-1} m_{i 2}\left(\hat{\gamma}_{2}\right)
\end{aligned}
$$

The best weighting matrix for two-step GMM estimation with a precisely characterized threshold regression models is shown in this study using a different approach. The goal is to use the reduced form parameter estimates to generate the optimal weighting matrix for the model. Reduced-form weighting estimator (RWE) is the name given to the resultant estimate in this work. Since the variance decomposition variable is precisely specified, unlike in generic two-step GMM, RWE does not have the higher-order asymptotic bias resulting from the selection of prior weighted matrices. A prolonged estimator and a RWE are statistically identical in linear simultaneous equation models. When the moment functions are linearized with respect to the reduced form component, the statistical comparability conclusion applies to a class of limited information linear regression.

\section{Econometric model}

The study aims to test the impact of climate risks on climate change mitigation, with the role of financial stability of a particular country. To infer this nexus, this study used the following equation:

$Y_{i t}=\alpha_{i} Y_{i t-1}+\beta T F S_{i t}+Y_{i t} X_{i t}+\delta_{i t} C C E_{i t}+v_{i}+\mu_{i}+\varepsilon_{i t}$

where designates the climate risks of G-5 countries $i$ at $t$ time, is a vector showing output effect of growth function, is the proxy of fiscal burden with, $\beta, \lambda$ and $\delta$ parameters. While,,, are country-specific, period-specific effects, and error terms respectively.

$\Delta Y_{i t}=\alpha_{i} \Delta Y_{i t-1}+\beta \Delta F S_{i t}+Y_{i t} \Delta X_{i t}+\delta_{i t} \Delta C C E_{i t}+\Delta v_{i}+\Delta \mu_{i}+\Delta \varepsilon_{i t}$

There are certain limitations in the vibrant model (Eq. 13) under the ordinary least square (OLS) method (Rashid and Naeem 2017). For this, it is a prerequisite to removing fixed effects by taking the first differences of variables. Equation (13) with first differences is written in Eq. (14).

\section{Results and Discussion}

\section{Empirical results}

The study findings indicate that the G-5 nations must work together to devise a plan for promoting financial stability in countries with fast industrial prosperity and significant changes to their financial systems (Tables 1 and 2). Economic collapse may have major consequences for these countries in terms of increased economic uncertainty, decreased growth in the economy and less effective capital investment distribution.

As part of their research on climate adaptation risks, Iqbal et al. $(2021 \mathrm{a}, \mathrm{b})$ look at how different scenarios for climate change adaptation. Although the Mexican financial system is only indirectly exposed to CPRS, financial contagion effects may impair monetary sustainability in the event of an amicable resolution and poor market circumstances. They apply this approach to a dataset of the Mexican financial system. Analyze the impact of climate finance regulatory and fiscal policies on transition using SFC modelling.

A strategy to lower capital requirements for green loans, known as the "green possible to put," has the potential to enhance banks' impact of financial since it leads to a rise in lending, which relies on less bank capital. According to Anh Tu et al. (2021), the green support factor's transition benefits are amplified when paired with financial stability. According to their findings (see Table 3), "dirty penalizing factors"- financial regulatory policies with a negative 
Table 1 Representation of empirical parameters

\begin{tabular}{ll}
\hline Denomination & Proxy title \\
\hline INV & Investment in green bonds for climate change mitigation \\
FV & Face value of green bonds \\
RVY & Recovery rate of finances through bond markets \\
M & Model \\
C & Country \\
Ca & Case \\
MS & Market share of green bonds in bond market \\
NEQ & National Equity capital invested for climate change mitigation \\
APV & Assets price volatility \\
ML & Market liquidity of green bonds \\
TCPS & Time of climate policy shock \\
MTC & Maturity of interbank contracts \\
FRCS & First round climate shock \\
SRCS & Second round climate shock \\
TRCS & Third round climate shock \\
LSEC & Losses shifted to external creditors \\
TSFC & Total shock by a financial contagion \\
TSCC & Total shock by a climate contagion \\
EL & Elasticity of green bonds demand \\
CCI & Climate Change Index to measure climate change mitigation \\
\hline
\end{tabular}

environmental impact-can have a negative impression on banks' short-term location financially because they raise the default probability in the non-financial financial industry.

Both have demonstrated that authorities" "charcoal tax income recycling" (i.e., the reinvestment of carbon tax funds) is required to accompany carbon tax measures in order to mitigate the potential distributional and financial impacts of carbon pricing. For example, the model developed by Iqbal et al. (2021a, b) adds economic actor predictions about the effect of climate policy on firm performance, which is a major invention. Companies' vulnerability to climate hazards, for example, might force financial institutions

Table 2 Descriptive statistics

\begin{tabular}{lllllc}
\hline $\begin{array}{l}\text { Constructs of finan- } \\
\text { cial stability }\end{array}$ & $2009-2013$ & & & $2014-2018$ & \\
\cline { 2 - 3 } & Median & SD & & Median & SD \\
\hline INV & 3.09 & 2.77 & 2.17 & 0.10 \\
FV & 6.56 & 0.23 & 0.99 & 0.67 \\
RVY & 3.11 & 5.52 & 4.46 & 17.8 \\
MS & 1.06 & 0.33 & 7.81 & 7.78 \\
NEQ & 1.50 & 1.29 & 3.99 & 5.01 \\
APV & 4.99 & 5.20 & 5.04 & 2.01 \\
ML & 2.19 & 6.11 & 1.23 & 3.09 \\
TCPS & 2.04 & 4.59 & 4.00 & 5.06 \\
MTC & 0.34 & 0.12 & 0.66 & 0.01 \\
EL & 0.11 & 0.64 & 0.23 & 0.09 \\
\hline
\end{tabular}

to adjust their lending strategies and capital costs. Financial players may now feedback their climate financial risk assessment into expenditures and policy choices made by enterprises, which gives a more accurate picture of finance's involvement in the low-carbon transition. According to Alemzero et al. (2021), when banks adjust their lending practices and loan costs in advance of a rise in the carbon price, they lessen the effect of the energy transition on financial stability.

It is believed that banks thought of the flood as a onetime thing. Li et al. (2021a, b) explained about multifaceted chart method combined with typical econometric tools is how they achieve it. According to their findings, climate-related factors have an influence on financial stability by raising or lowering commodity prices (see Table 4 and Fig. 1).

Three pieces in this special edition examine the impact of climate change on financial market pricing. It is Zhao et al. (2021) who paid attention to the bond market. Using a compounded Poisson process, this study provides a model for default able bonds that incorporates transition risk. Bond prices may be influenced by a sudden shift in climate policy, which manifests itself as a drop in the value of a company's stock and so increases the likelihood of a default. If greener bond rates are lower than the conventional bond yields, Barrett et al. (2021) conduct an econometric study to find out. While rates are lower for international entities and non-financial firms, there is no difference in the yields of green bonds and conventional 
Table 3 Empirical parameters of climate risks of G-5' economies

\begin{tabular}{lcllc}
\hline Variables & Actual value & $\begin{array}{l}\text { Climate risk } \\
\text { level }\end{array}$ & High rate & Climate shock \\
\hline FRCS & 176.1 & 444.7 & 0.85 & 40.44 \\
SRCS & 333.9 & 482.1 & 0.90 & 0.35 \\
TRCS & 244.5 & 233.8 & 0.83 & 80.3 \\
LSEC & 737.0 & 555.1 & 0.32 & 63.4 \\
TSFC & 103.8 & 101.1 & 0.10 & 495.1 \\
TSCC & 2.75 & 35.10 & 0.03 & 10.01 \\
CCI & 3.13 & 32.13 & 0.01 & 10.76 \\
\hline
\end{tabular}

bonds for financial institutions; they discover diverse impacts. They also discover that the green bond yields are lower in the event of recurrent green corporate bonds and then when the green bond certification procedure is reviewed by an external agency. In addition, banks that issue green bonds have been shown to limit the amount of money they lend to dioxide industries.

\section{Robustness}

For offsetting climate-related risks, financial tools such as climate and weather derivatives may be beneficial. Copulabased price approach for climate and weather derivatives analysis is introduced by Liu and Yang (2021). They conduct an empirical study using Italian data and find that the optimum copula selection varies depending on season being studied. There are additional problems with climate and weather derivatives prices, as well as how undervaluation may exacerbate physical dangers while compromising financial stability (see Table 5 and Fig. 2).

In order to achieve and sustain financial stability, political and social agreement must be present. As actual economic problems arise, a strong financial sector is less vulnerable to financial crises and more resilient to them when they do happen. Reforms are often needed immediately, but the time it takes to accomplish them varies widely based on the kind of change and whether or not suitable timing is necessary. The security council may help by defining a set of sound financial ability to scale standards and procedures in a participatory way and by supporting the adoption and implementation of these standards and procedures.

\section{IMF response to financial stability for climate change mitigation}

For an in-depth look at the global financial system and markets, the Global Financial Stability Report is an excellent resource. Current market circumstances are highlighted, as are systemic problems that might jeopardize financial
Table 4 One-step and two-step GMM estimates

\begin{tabular}{|c|c|c|c|c|}
\hline & $\begin{array}{l}\text { One step } \\
\text { (1) }\end{array}$ & $\begin{array}{l}\text { Two step } \\
\text { (2) }\end{array}$ & $\begin{array}{l}\text { One step } \\
\text { (3) }\end{array}$ & $\begin{array}{l}\text { Two step } \\
\text { (4) }\end{array}$ \\
\hline INV & $0.312 * * *(0.002)$ & $0.049^{* *}(0.000)$ & $0.244 * * *(0.000)$ & $0.606 * *(0.000)$ \\
\hline $\mathrm{FV}$ & $0.111 * * *(0.001)$ & $0.133^{* * *}(0.000)$ & $0.290 * * *(0.000)$ & $0.892 * * *(0.001)$ \\
\hline RVY & $0.089 * *(0.000)$ & $0.085(0.000)$ & $0.013 * *(0.000)$ & $0.054 *(0.071)$ \\
\hline MS & $0.395 * * *(0.000)$ & $0.096^{* *}(0.000)$ & $0.074 * * *(0.001)$ & $0.005 *(0.000)$ \\
\hline NEQ & $0.078(0.031)$ & $0.037 *(0.001)$ & $0.049(0.000)$ & $0.067(0.094)$ \\
\hline APV & $0.574 * * *(0.035)$ & $0.567 * * *(0.003)$ & $0.634 * * *(0.000)$ & $0.337 * * *(0.001)$ \\
\hline ML & $0.77 * *(0.000)$ & $0.67 * *(0.000)$ & $0.81 * *(0.000)$ & $0.86^{* *}(0.000)$ \\
\hline TCPS & $0.34 * *(0.000)$ & $0.41(0.000)$ & $0.41 * *(0.000)$ & $0.46(0.000)$ \\
\hline MTC & $0.11 * *(0.000)$ & $0.16^{* *}(0.000)$ & $0.19 *(0.000)$ & $0.25 * *(0.000)$ \\
\hline FRCS & $0.45^{* *}(0.000)$ & $0.45(0.000)$ & $0.40 * *(0.000)$ & $0.38 * *(0.000)$ \\
\hline SRCS & $0.20(0.000)$ & $0.22 * *(0.000)$ & $0.28 * *(0.000)$ & $0.25 * *(0.000)$ \\
\hline TRCS & $0.66^{* *}(0.000)$ & $0.57 * *(0.000)$ & $0.71(0.000)$ & $0.69 * *(0.000)$ \\
\hline LSEC & $0.34 * *(0.000)$ & $0.37(0.000)$ & $0.41 * *(0.000)$ & $0.48(0.000)$ \\
\hline TSFC & $0.10 * *(0.000)$ & $0.16 * *(0.000)$ & $0.13 * *(0.000)$ & $0.14 * *(0.000)$ \\
\hline TSCC & $0.35(0.000)$ & $0.10(0.000)$ & $0.17 * *(0.000)$ & $0.22 * *(0.000)$ \\
\hline EL & $0.32 * *(0.000)$ & $0.30(0.000)$ & $0.35(0.000)$ & $0.37(0.000)$ \\
\hline CCI & $0.77 * *(0.000)$ & $0.71 * *(0.000)$ & $0.80 * *(0.000)$ & $0.14(0.000)$ \\
\hline Adjusted $R^{2}$ & 0.85 & & 0.89 & \\
\hline Arellano-bond AR (1) & $-3.445[0.002]$ & & & $-2.919[0.004]$ \\
\hline Arellano-bond AR (2) & $-0.672[0.514]$ & & & $-0.689[0.533]$ \\
\hline Sargan test & $341.011[0.8561]$ & & & $301.334[0.882]$ \\
\hline
\end{tabular}

$p$ value in brackets and standard errors in parentheses; $* p<0.1, * * p<0.5, * * * p<0.01$ 
Fig. 1 Country-wise climate risk conditions

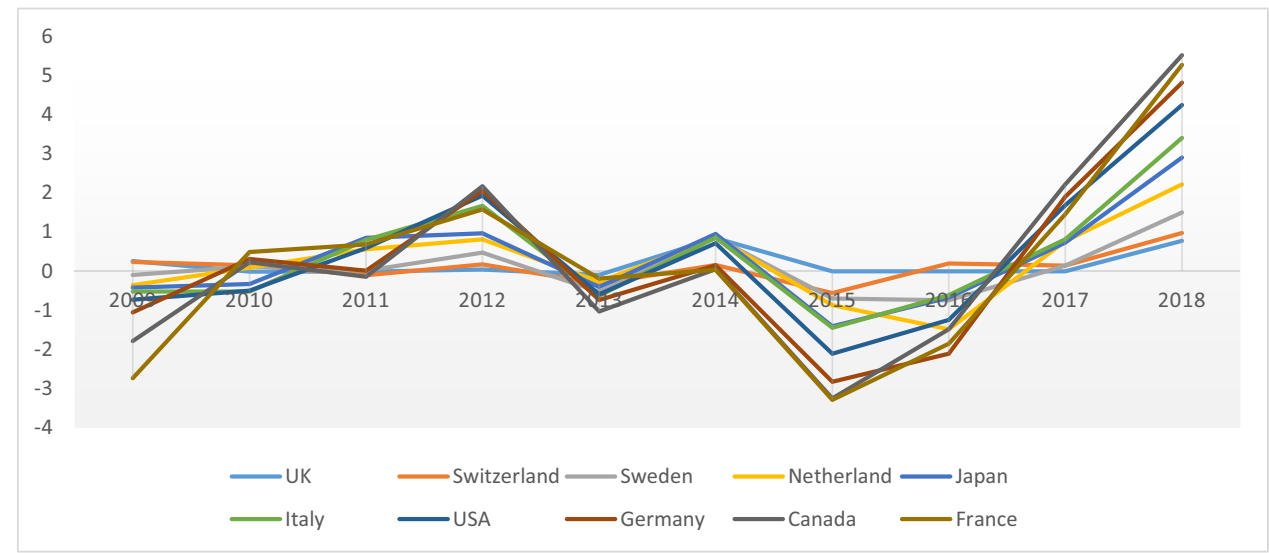

\begin{tabular}{|c|c|c|c|c|c|c|}
\hline & \multicolumn{3}{|c|}{ 2009-2013 } & \multicolumn{3}{|c|}{ 2014-2018 } \\
\hline & FS & CR & CCE & FS & CR & $\mathrm{CCE}$ \\
\hline $\begin{array}{l}\text { Financial stability } \mathrm{t}-1 \\
\text { Wald test } \\
\text { Significance }\end{array}$ & $\begin{array}{l}0.701 \\
{[0.23]^{*}} \\
(0.000)\end{array}$ & $\begin{array}{l}0.338 \\
{[0.29]^{*}} \\
(0.000)\end{array}$ & $\begin{array}{l}0.628 \\
{[0.37]^{*}} \\
(0.000)\end{array}$ & $\begin{array}{l}6.237 \\
{[2.77]^{*}} \\
(0.000)\end{array}$ & $\begin{array}{l}6.001 \\
{[2.43]^{* *}} \\
(0.000)\end{array}$ & $\begin{array}{l}5.449 \\
{[3.01]^{* *}} \\
(0.000)\end{array}$ \\
\hline $\begin{array}{l}\text { Climate risk }{ }_{t-1} \\
\text { Wald test } \\
\text { Significance }\end{array}$ & $\begin{array}{l}2.36 \\
{[2.01]} \\
(0.000)\end{array}$ & $\begin{array}{l}2.11 \\
{[2.99]} \\
(0.000)\end{array}$ & $\begin{array}{l}2.02 \\
{[2.63]} \\
(0.000\end{array}$ & $\begin{array}{l}3.67 \\
{[3.63]^{*}} \\
(0.000)\end{array}$ & $\begin{array}{l}3.143 \\
{[3.22]^{* *}} \\
(0.000)\end{array}$ & $\begin{array}{l}2.967 \\
{[3.94]} \\
(0.000)\end{array}$ \\
\hline $\begin{array}{l}\text { Climate change mitigation }{ }_{t-1} \\
\text { Wald test } \\
\text { Significance }\end{array}$ & $\begin{array}{l}4.02 \\
{[0.32]} \\
(0.000)\end{array}$ & $\begin{array}{l}4.65 \\
{[0.49]} \\
(0.000)\end{array}$ & $\begin{array}{l}4.78 \\
{[0.95]} \\
(0.000)\end{array}$ & $\begin{array}{l}5.19 \\
{[0.10]} \\
(0.000)\end{array}$ & $\begin{array}{l}4.88 \\
{[0.10]} \\
(0.000)\end{array}$ & $\begin{array}{l}5.07 \\
{[0.13]} \\
(0.000)\end{array}$ \\
\hline
\end{tabular}

Fig. 2 Financial stability trends

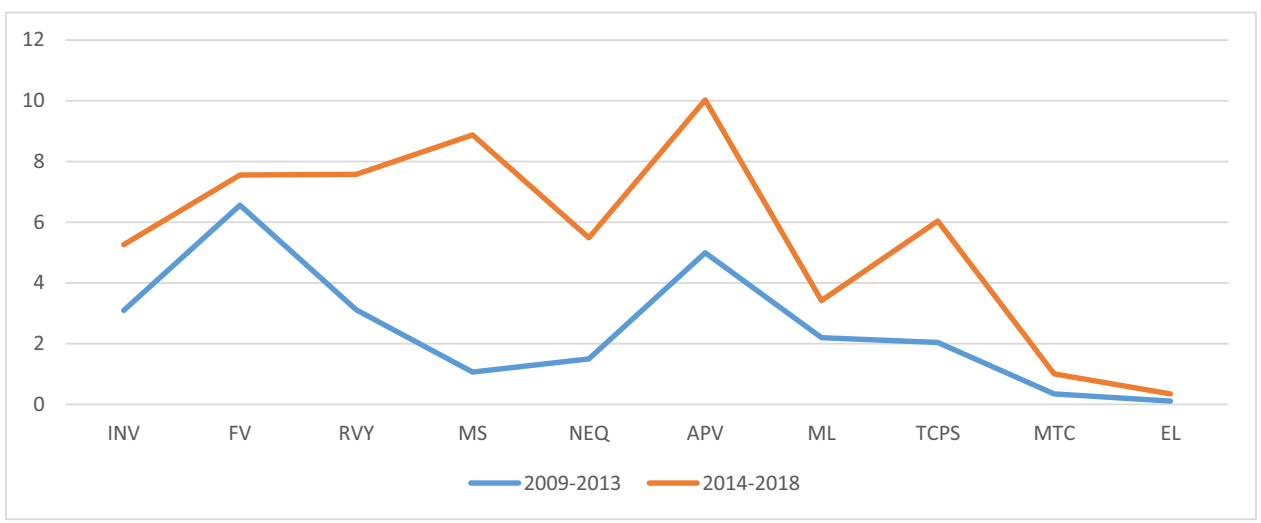

stability and limit developing market borrowers' access to credit. According to the IMF's World Economic Outlook, macroeconomic inequalities have financial repercussions. It contains a section or articles that analyses fundamental or fundamental problems that are important to international financial stability as a special feature.

As a result of continued economic assistance and a worldwide economic recovery early this year, financial stability concerns have been minimized. First, the chapter describes how economic circumstances in industrialized economies have improved more on net, whereas in developing markets, they have remained stable. A combination of mounting doubts about the robustness of the global economy and continued disruptions has exacerbated inflationary pressures, dampening investor confidence. Some economic sectors continue to show signs of stretched asset values, and the sense of the word financial sector still has weaknesses; the business sector's rebound is patchy. The crypto ecosystem's prospects and difficulties are discussed in detail in Chapter 2. Significant data gaps endanger economic stability because 
crypto asset providers lack operational or security resistance. Emerging-market crypto assets may hasten the process of currency devaluation. Sustainability investments may help with the worldwide shift to a sustainable future, but they need to be scaled up to have a significant influence, as shown in Chapter 3. Other topics include the potential for future disruption in the investment group industry due to an unruly transformation.

\section{Discussion}

There are still gaps in various areas of climate finance that will be filled by the contributions in this special issue, including, Global warming research that makes use of network finance modelling on a regular basis. A comprehensive understanding of transitions and environmental risk socioeconomic and socio feedback mechanisms is especially crucial for this (Huang et al. 2021). Research on whether or whether finance can help or hinder the reduced transformation. Identifying climate mitigation paths that allow for the accomplishment of the Paris Agreement's aims necessitates understanding the ambiguous role of money in mitigation scenarios. Monetary climate policy modelling and study of the effects on particular country's financial systems of interconnections between fiscal, monetary, and financial policy climate policies. climate risk assessment in light of the COVID-19 crisis and development of COVID-19 rehabilitation measures that are climate-friendly (Iqbal and Bilal 2021).

This study, conducted by Anh Tu et al. (2021), focuses on financial markets. They first demonstrate that investors accept a lower reward for owning shares of businesses that publish environmental data and have a lower emission intensity using a sample from the side of the Europe Total Market Index. They then calculate the worldwide loss for perceptions of organizational if stocks of firms with a strong environmental and transparency character beat those of fuel industries. In their research, the losses are not quantifiably high, which is at least in part due to the fact that first wave impacts are not taken into account (Zhang et al. 2021). They also demonstrate that rebalancing portfolios in favor of more environmentally friendly investments might help to mitigate these losses.

Ultimately, this new issue contributes to the discussion on climate risk and financial stability by providing evidence from research. Research in the aforementioned domains is critical to assist the following parties: Academics must provide evidence-based outcomes and assistance lawmakers in developing strategies to address climate-related financial risks; central banks and large supervisors should incorporate climatic change factors into their financial risk assessment tools (such as stress tests) and supervisory regulations, and they should meet their price and financial stability mandates in the wake of the climate crisis; and shareholders should end up making their holdings publicly available.

\section{Conclusion and implications}

A new mechanism of financial system risk has just been identified: climate change. Recently, a number of financial institutions and corporate watchdogs have advised shareholders and investment firms to evaluate their exposure to climate-related financial risks. As a result, national banks and large regulators have begun developing scenarios for climate stress tests in order to determine how changing climate would influence the economic sector. Despite this, the finance system lacks procedures that would allow for a thorough assessment of climate change's potential impact on financial stability. Conventional methodologies to macroeconomic and financial risk analysis are put to the test by climate risk features (such as profound ambiguity, quasi, and indigeneity). For a complete understanding of climatic anthropogenic climate words used to describe importance, fresh views on climate change must be included into macrofinancial analyses. Here, the relationship between climate risk and economic security is explored for the very first time, with a focus on bridging analytical limitations and shedding light on the economic consequences of climate change. To better understand climate-related financial risks and the implications of financial policies and instruments aimed at a low-carbon transition, the book contains unique contribution that employ a variety of methodologies, such as network modelling, constantly changes macroeconomic modelling, and financial microeconomics These contributors' research findings may help central banks and financial regulators integrate global warming concerns into their policies and financial risk evaluation, which can help them make better judgments.

Members of the G-10 and emerging market nations develop a worldwide agreement on the most important aspects of a good economic and legal system: incorporation of international institutions such as the Basle Committee, the International Association of Insurance Supervisors (IAIS), and IOSCO to develop standards, principles, and procedures; encouragement for good emphasizing, better corporate management, and other critical characteristics of a strong financial sector via the use of market discipline and market access channels; acceptance and execution of good ideas and practices promoted by international organizations like the IMF, the World Bank, and the regional development banks. 
Three essential implications for green economic recovery have driven the taskforce in formulating this tactic:

- Public governments, who have a vested interest in creating solid financial system arrangements, must bear full responsibility for measures adopted to enhance banking institutions.

- Global supervisory norms and competitor, expert, and clear market structure based on reasonable standards and procedures that generate relevant information and appropriate incentives are the most likely ways to achieve finance industry consistency in an integrated global economy.

- To avoid or at least limit the creation of major financial imbalances, misleading pricing signaling, and incentives distortions, sound macroeconomic and structural policies are required.

Following such implications, the study suggests following some future research directions that are the probable path that can be pursued in future research.

- To date, several climate change programs have tried to fight pollution by growing human activity's impact on the amount of greenhouse gases. Despite widespread attempts to combat climate change, $\mathrm{CO} 2$ pollution, growth in the economy is rising because of an increase in emissions from fossil fuel-burning power plants and worldwide electricity and transport use.

- Emissions from these two regions account for half and a fifth of global emissions. It has at the same time negatively impacted electricity networks and multinational supply chains. The key aim of productivity initiatives is to boost fuel economy and reduce global warming pollution in the automotive fleet. After having accomplished a lot of change in that regard, though, the overall oil use and distance travelled by cars still continue to increase; thus, carbon emissions continue to climb.

- Applying any policies to reduce greenhouse pollution is easier than trying to deal with the consequences of climate change. But, long-term benefits can emerge only at the global level. Adaptation has more advantages in the short term than in the long term or also in the medium term. This raises a concern because reneging on mitigation promises may be profitable. For the present purposes, it will make economic and social sense to expend less on prevention but, from a global perspective, respond to reduced climate change impacts (if any). It is perfectly understandable why citizens (and taxpayers) are typically fiscally conservative in deciding not to support policies that have benefits primarily for other countries given the local dynamics of political competition.

Author contribution Conceptualization, visualization: Licheng Sun. Visualization, editing, writing of draft: Sui Fang. Review, editing and supervision: Ahmad Raza Bilal. Writing, methodology and software: Sajid Iqbal.

Data availability The data that support the findings of this study are openly available on request.

\section{Declarations}

Competing interests The authors declare no competing interests.

Competing interests The authors declare no competing interests.

\section{References}

Ahmad B, Iqbal S, Hai M, Latif S (2021) The interplay of personal values, relational mobile usage and organizational citizenship behavior. Interact Technol Smart Educ

Aikman D, Haldane AG, Hinterschweiger M, Kapadia S (2019) Rethinking financial stability. Blanchard O. e Summers LH (a cura di), Evolution or Revolution, 143-194

Alan S, Attanasio O, Browning M (2009) Estimating Euler equations with noisy data: two exact GMM estimators. J Appl Econ 24(2):309-324

Alemzero DA, Iqbal N, Iqbal S, Mohsin M, Chukwuma NJ, Shah BA (2021) Assessing the perceived impact of exploration and production of hydrocarbons on households perspective of environmental regulation in Ghana. Environ Sci Pollut Res 28(5):5359-5371

Alqahtani F, Mayes DG (2018) Financial stability of Islamic banking and the global financial crisis: Evidence from the Gulf Cooperation Council. Econ Syst 42(2):346-360

Anadu K, Kruttli MS, McCabe PE, Osambela E (2020) The shift from active to passive investing: potential risks to financial stability?. Available at SSRN 3244467

Anarfo EB, Abor JY (2020) Financial regulation and financial inclusion in Sub-Saharan Africa: does financial stability play a moderating role? Res Int Bus Financ 51:101070

Anh Tu C, Chien F, Hussein MA, Ramli MMY, Psi MMMSS, Iqbal S, Bilal AR (2021) Estimating role of Green Financing on Energy Security, Economic and Environmental Integration of BRI member countries. Singap Econ Rev

Arbuckle JG Jr, Morton LW, Hobbs J (2015) Understanding farmer perspectives on climate change adaptation and mitigation: the roles of trust in sources of climate information, climate change beliefs, and perceived risk. Environ Behav 47(2):205-234

Bain PG, Hornsey MJ, Bongiorno R, Jeffries C (2012) Promoting pro-environmental action in climate change deniers. Nat Clim Chang 2(8):600-603

Barbi F, da Costa Ferreira L (2017) Governing climate change risks: subnational climate policies in Brazil. Chin Polit Sci Rev 2(2):237-252 
Barnett J (2003) Security and climate change. Glob Environ Chang 13(1):7-17

Barrett P, Bondar M, Chen S, Chivakul M, Igan DO, Peria MSM (2021) Pricing protest: the response of financial markets to social unrest. IMF Working Papers, 2021(079)

Bovari E, Giraud G, McIsaac F (2020) Financial impacts of climate change mitigation policies and their macroeconomic implications: a stock-flow consistent approach. Clim Policy 20(2): 179-198

Buckmann M, Haldane A, Hüser AC (2021) Comparing minds and machines: implications for financial stability. Oxf Rev Econ Policy 37(3):479-508

Campbell BM, Vermeulen SJ, Aggarwal PK, Corner-Dolloff C, Girvetz E, Loboguerrero AM, ... Wollenberg E (2016) Reducing risks to food security from climate change. Glob Food Sec 11:34-43

Carney M (2015) Breaking the tragedy of the horizon-climate change and financial stability. Speech given at Lloyd's of London 29:220-230

Chen AA, Stephens AJ, Koon RK, Ashtine M, Koon KMK (2020) Pathways to climate change mitigation and stable energy by $100 \%$ renewable for a small island: Jamaica as an example. Renew Sustain Energy Rev 121:109671

Creutzig F, Ravindranath NH, Berndes G, Bolwig S, Bright R, Cherubini F, ... Masera O (2015) Bioenergy and climate change mitigation: an assessment. Gcb Bioenergy 7(5):916-944

Demski C, Capstick S, Pidgeon N, Sposato RG, Spence A (2017) Experience of extreme weather affects climate change mitigation and adaptation responses. Clim Chang 140(2):149-164

Doelman JC, Stehfest E, van Vuuren DP, Tabeau A, Hof AF, Braakhekke MC, ... Lucas PL (2020) Afforestation for climate change mitigation: potentials, risks and trade-offs. Glob Chang Biol 26(3):1576-1591

Drobyazko S, Barwinska-Malajowicz A, Slusarczyk B, Chubukova O, Bielialov T (2020) Risk management in the system of financial stability of the service enterprise. J Risk Financ Manag 13(12):300

Flori A, Pammolli F, Spelta A (2021) Commodity prices co-movements and financial stability: a multidimensional visibility nexus with climate conditions. J Financ Stabil 54:100876

Giuzio M, Krušec D, Levels A, Melo AS, Mikkonen K, Radulova P (2019) Climate change and financial stability. Financ Stabil Rev 1

Gupta J, Kashiramka S (2020) Financial stability of banks in India: does liquidity creation matter? Pac Basin Financ J 64:101439

Hansen LP, Heaton J, Yaron A (1996) Finite-sample properties of some alternative GMM estimators. J Bus Eco Stat 14(3):262-280

Hasegawa T, Fujimori S, Havlík P, Valin H, Bodirsky BL, Doelman JC, ... Witzke P (2018) Risk of increased food insecurity under stringent global climate change mitigation policy. Nat Clim Chang 8(8):699-703

Howell RA, Capstick S, Whitmarsh L (2016) Impacts of adaptation and responsibility framings on attitudes towards climate change mitigation. Clim Chang 136(3-4):445-461

Huang J, Wang X, Liu H, Iqbal S (2021) Financial consideration of energy and environmental nexus with energy poverty: Promoting financial development in G7 economies. Front Energy Res, 666

Inoune M, Iwasaki M, Otani T, Sasazuki S, Noda M, Tsugane S, \& Japan Public Health Center-Based Prospective Study Group (2006) Diabetes mellitus and the risk of cancer: results from a large-scale population-based cohort study in Japan. Archives of internal medicine, 166(17), 1871-1877.

Iqbal, S., \& Bilal, A. R. (2021). Investment performance: emotional beasts are dragging into the darkness of the castle. Global Business Review, 09721509211044309
Iqbal S, Bilal AR (2021) Energy financing in COVID-19: how public supports can benefit?. China Finance Rev Int

Iqbal S, Bilal AR, Nurunnabi M, Iqbal W, Alfakhri Y, Iqbal N (2021a) It is time to control the worst: testing COVID-19 outbreak, energy consumption and CO 2 emission. Environ Sci Pollut Res 28(15):19008-19020

Iqbal S, Taghizadeh-Hesary F, Mohsin M, Iqbal W (2021) Assessing the role of the green finance index in environmental pollution reduction. Stud Appl Econ 39(3)

Ivanova D, Barrett J, Wiedenhofer D, Macura B, Callaghan M, Creutzig F (2020) Quantifying the potential for climate change mitigation of consumption options. Environ Res Lett 15(9):093001

Kim H, Batten JA, Ryu D (2020) Financial crisis, bank diversification, and financial stability: OECD countries. Int Rev Econ Financ 65:94-104

Kopp, E., Kaffenberger, L., \& Wilson, C. (2017). Cyber risk, market failures, and financial stability. International Monetary Fund

Lasco RD, Delfino RJP, Espaldon MLO (2014) Agroforestry systems: helping smallholders adapt to climate risks while mitigating climate change. Wiley Interdiscip Rev Clim Chang 5(6):825-833

Lee SY (2012) Corporate carbon strategies in responding to climate change. Business Strategy and the Environment, 21(1):33-48

Li W, Chien F, Hsu CC, Zhang Y, Nawaz MA, Iqbal S, Mohsin M (2021) Nexus between energy poverty and energy efficiency: estimating the long-run dynamics. Resour Policy 72:102063

Li W, Chien F, Ngo QT, Nguyen TD, Iqbal S, Bilal AR (2021) Vertical financial disparity, energy prices and emission reduction: empirical insights from Pakistan. Journal of Environ Manag 294:112946

Liu C, Zheng Y, Zhao Q, Wang C (2020) Financial stability and real estate price fluctuation in China. Phys A Stat Mech Appl 540:122980

Liu Z, Yang Y (2021) Barrier swaption pricing problem in uncertain financial market. Math Methods Appl Sci 44(1):568-582

McMichael AJ, Lindgren E (2011) Climate change: present and future risks to health, and necessary responses. J Intern Med 270(5):401-413

Mi Z, Guan D, Liu Z, Liu J, Viguié V, Fromer N, Wang Y (2019) Cities: the core of climate change mitigation. J Clean Prod 207:582-589

Mills E (2007) Synergisms between climate change mitigation and adaptation: an insurance perspective. Mitig Adapt Strat Glob Chang 12(5):809-842

Moser SC, Luers AL (2008) Managing climate risks in California: the need to engage resource managers for successful adaptation to change. Clim Change 87(1):309-322

Nair AR, Anand B (2020) Monetary policy and financial stability: should central bank lean against the wind? Central Bank Review 20(3):133-142

Neuhoff, K., Fankhauser, S., Guerin, E., Hourcade, J. C., Jackson, H., Rajan, R., \& Ward, J. (2009). Structuring international financial support to support domestic climate change mitigation in developing countries. Climate Strategies..

Ogunbode CA, Böhm G, Capstick SB, Demski C, Spence A, Tausch N (2019) The resilience paradox: flooding experience, coping and climate change mitigation intentions. Clim Policy 19(6):703-715

Park S, Gupta S (2012) Comparison of SML and GMM estimators for the random coefficient logit model using aggregate data. Empir Econ 43(3):1353-1372

Phan DHB, Iyke BN, Sharma SS, Affandi Y (2021) Economic policy uncertainty and financial stability-is there a relation? Econ Model 94:1018-1029

Puaschunder JM (2016) Intergenerational climate change burden sharing: an economics of climate stability research agenda proposal. Glob J Manag Bus Res Econ Commerce 16(3):31-38

Rashid A, Naeem N (2017) Effects of mergers on corporate performance: an empirical evaluation using OLS and the empirical Bayesian methods. Borsa Istanbul Rev 17(1):10-24 
Revi A (2008) Climate change risk: an adaptation and mitigation agenda for Indian cities. Environ Urban 20(1):207-229

Rickards L, Wiseman J, Kashima Y (2014) Barriers to effective climate change mitigation: the case of senior government and business decision makers. Wiley Interdiscip Rev Clim Chang 5(6):753-773

Ronchetti E, Trojani F (2001) Robust inference with GMM estimators. J Econ 101(1):37-69

Sholdarov D, Mullaboev B (2019) Problems of supporting financial stability of the pension supply system in Uzbekistan. Theor Appl Sci 2:344-349

Stephens JC, Rand GM, Melnick LL (2009) Wind energy in US media: a comparative state-level analysis of a critical climate change mitigation technology. Environ Commun 3(2):168-190

Sussman FG, Freed JR (2008) Adapting to climate change: a business approach. Pew Center on Global Climate Change, Arlington, p 41

Swim JK, Stern PC, Doherty TJ, Clayton S, Reser JP, Weber EU, ... Howard GS (2011) Psychology's contributions to understanding and addressing global climate change. Am Psychol 66(4):241

Tong S, Ebi K (2019) Preventing and mitigating health risks of climate change. Environ Res 174:9-13

Trinh VQ, Elnahass M, Salama A, Izzeldin M (2020) Board busyness, performance and financial stability: does bank type matter? Eur J Financ 26(7-8):774-801

VijayaVenkataRaman S, Iniyan S, Goic R (2012) A review of climate change, mitigation and adaptation. Renew Sustain Energy Rev 16(1):878-897

Viscusi WK, Zeckhauser RJ (2006) The perception and valuation of the risks of climate change: a rational and behavioral blend. Clim Chang 77(1):151-177
Warren R, VanDerWal J, Price J, Welbergen JA, Atkinson I, RamirezVillegas J, ... Lowe J (2013) Quantifying the benefit of early climate change mitigation in avoiding biodiversity loss. Nat Clim Chang 3(7):678-682

Weber C, McCollum DL, Edmonds J, Faria P, Pyanet A, Rogelj J, ... Kriegler E (2018) Mitigation scenarios must cater to new users. Nat Clim Chang 8(10):845-848

Weber EU (2010) What shapes perceptions of climate change? Wiley Interdiscip Rev Clim Chang 1(3):332-342

Wennersten R, Sun Q, Li H (2015) The future potential for carbon capture and storage in climate change mitigation-an overview from perspectives of technology, economy and risk. J Clean Prod 103:724-736

Windmeijer F (2005) A finite sample correction for the variance of linear efficient two-step GMM estimators. J Econ 126(1):25-51

Yin H (2019) Bank globalization and financial stability: international evidence. Res Int Bus Financ 49:207-224

Zhao P, Pan J, Yue Q, Zhang J (2021) Pricing of financial derivatives based on the Tsallis statistical theory. Chaos Sol Fractals 142:110463

Zhang L, Huang F, Lu L, Ni X, Iqbal S (2021) Energy financing for energy retrofit in COVID-19: Recommendations for green bond financing. Environmental Science and Pollution Research, 1-12

Publisher's note Springer Nature remains neutral with regard to jurisdictional claims in published maps and institutional affiliations. 